\section{R\&D on divertor plasma facing components at the Institute for Plasma Research}

\author{
Yashashri Patil, \\ S. Khirwadkar, \\ S. M. Belsare, \\ Rajamannar Swamy, \\ M. S. Khan, \\ S. Tripathi, \\ K. Bhope
}

\begin{abstract}
This paper is focused on various aspects of the development and testing of water cooled divertor PFCs. Divertor PFCs are mainly designed to absorb the heat and particle fluxes outflowing from the core plasma of fusion devices like ITER. The Divertor and First Wall Technology Development Division at the Institute for Plasma Research (IPR), India, is extensively working on development and testing of divertor plasma facing components (PFCs). Tungsten and graphite macro-brush type test mock-ups were produced using vacuum brazing furnace technique and tungsten monoblock type of test mock-ups were obtained by hot radial pressing (HRP) technique. Heat transfer performance of the developed test mock-ups was tested using high heat flux tests with different heat load conditions as well as the surface temperature monitoring using transient infrared thermography technique. Recently we have established the High Heat Flux Test Facility (HHFTF) at IPR with an electron gun EH300V (M/s Von Ardenne Anlagentechnik GmbH, Germany) having maximum power $200 \mathrm{~kW}$. Two tungsten monoblock type test mock-ups were probed using HHFTF. Both of the test mock-ups successfully sustained 316 thermal cycles during high heat flux (HHF) tests. The test mock-ups were non-destructively tested using infrared thermography before and after the HHF tests. In this note we describe the detailed procedure used for testing macro-brush and monoblock type test mock-ups using in-house transient infrared thermography set-up. An acceptance criteria limit was defined for small scale macro-brush type of

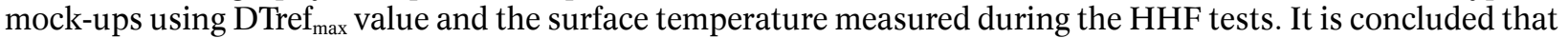
the heat transfer behavior of a plasma facing component was checked by the HHF tests followed by transient IR thermography. The acceptance criteria DTref ${ }_{\max }$ limit for a graphite macro-brush mock-up was found to be $\sim 3^{\circ} \mathrm{C}$ while for a tungsten macro-brush mock-up it was $\sim 5^{\circ} \mathrm{C}$.
\end{abstract}

Key words: divertor $\bullet$ plasma facing material $\bullet$ high heat flux test $\bullet$ transient IR thermography

Y. Patil $^{\bowtie}$, S. Khirwadkar, S. M. Belsare, R. Swamy, M. S. Khan, S. Tripathi, K. Bhope

Divertor and First Wall Technology

Development Division,

Institute for Plasma Research,

Bhat, Gandhinagar-382428, Gujarat, India,

Tel.: +91 7923962037 ,

E-mail: ypatil@ipr.res.in

Received: 30 June 2014

Accepted: 7 January 2015

\section{Introduction}

Nuclear fusion is promising way to generate electrical energy. The International Thermonuclear Experimental Fusion Reactor (ITER) is now being built to demonstrate the scientific and technical feasibility of fusion power [1]. A divertor is a crucial in-vessel component of a fusion reactor, designed to absorb and channel away the power deposited at its plates by plasma heat conduction, heat convection electromagnetic radiation or neutrons. The heat flux to which the ITER divertor would be probably exposed is estimated to be $10 \mathrm{MW} / \mathrm{m}^{2}$ in average, with $20 \mathrm{MW} / \mathrm{m}^{2}$ peak and transient heat fluxes of $100 \mathrm{MW} / \mathrm{m}^{2}$ for few milliseconds [2]. The inner and outer vertical targets and dome are the plasma facing components (PFCs) of the ITER-like divertor. Plasma facing materials for divertor PFCs have to withstand-in a steady state and transient loads neu- 
tron impact, tritium implantation, as well as chemi$\mathrm{cal}$ and physical sputtering. This requires specific thermal properties for the most efficient heat transfer and for acceptable degradation during the neutron irradiation. Due to these requirements the number of candidates for the divertor PFCs is limited [3]. Tungsten and tungsten alloys having high melting point do satisfy the above requirements and for this reason are considered to be prime candidates for the divertor PFCs as well as the first wall material in DEMO reactor. Plasma facing materials are joined to the $\mathrm{CuCrZr}$ alloy heat sink in either macro-brush or monoblock type geometry. An arrangement of plasma facing material (tungsten) tiles with a length of $\sim 10 \mathrm{~mm}$ attached to the CuCrZr alloy heat sink block is called a macro-brush type mock-up. An arrangement of monoblock shaped blocks of plasma facing material joined with an inner CuCrZr alloy heat sink tube is called a monoblock type mock-up. Brazing, electron beam welding and diffusion bonding are suitable joining techniques used for fabrication of divertor PFCs. During such manufacturing processes the joint integrity of PFCs is affected by defects in the form of delamination and cracks. A defect at joint integrity affects the heat transfers properties of PFCs and it may lead to component failure during reactor operation. Defect free PFC joint and identification of the location and the size of defects are the main challenges that any PFC developer has to face. Early detection of potential defects at the joint interlayer is provided by transient infrared thermography and ultrasonic testing of PFCs. The performance of divertor PFCs under steady state heat load is checked by high heat flux tests using charged particles and neutral beams. A high heat flux (HHF) test with desirable heat load followed by the transient infrared thermography is a suitable way to control the quality of divertor PFCs [4].

The Divertor and First Wall Development Division at IPR is extensively working on development and testing of divertor PFCs. Tungsten and graphite macro-brush type test mock-ups were developed using vacuum brazing furnace technique and monoblock type of test mock-ups were obtained by hot radial pressing (HRP) technique. These test mock-ups were examined using HHF tests and the transient infrared thermography. The results obtained formed the basis on which acceptance criteria have been defined for testing and qualifying the small scale test macro-brush type mock-ups. Recently we have established at IPF the High Heat Flux Test Facility (HHFTF) and tungsten monoblock-type mock-ups have been tested using HHFTF at IPR. Apart from HHF tests, the Divertor Division at IPR is presently developing tungsten and tungsten alloy materials to improve thermo-mechanical properties using a powder metallurgical root. Thermal properties of the developed materials, procured tungsten materials, brazed joints, and various coatings were measured using the laser flash thermal diffusivity measurement system. Along with transient IR thermograph an ultrasonic immersion C-scan testing technique had been used for quality control of divertor test mock-up.

\section{Development of divertor small scale test mock-ups}

\section{Macro-brush type mock-up}

The graphite and tungsten macro-brush type mock-ups were obtained with the use of high temperature vacuum brazing technique. Tungsten and graphite square tiles with dimensions of $10 \mathrm{~mm} \times 10 \mathrm{~mm}$ were machined into 5 and $10 \mathrm{~mm}$ thick tiles, respectively, with the use of an electric discharge machine (EDM). Oxygen free high thermal conductivity (OFHC) copper was cast on each tile at the temperature of $1125^{\circ} \mathrm{C}$. OFHC copper casted tiles were brazed to a $\mathrm{CuCrZr}$ alloy heat sink using desirable brazing filler NiCuMn-37 for copper to copper alloy joint [5].

\section{Monoblock type mock-up}

Tungsten monoblock type mock-up was obtained with the use of high temperature high pressure diffusion bonding process at NFTDC Hyderabad. The mock-up consisted of five tungsten alloy (W-1\%La2O3) monoblocks with a $0.5 \mathrm{~mm}$ gap joined to actively cooled $\mathrm{CuCrZr}$ alloy heat sink tube. Figure 1 shows the photograph of tungsten macro-brush and monoblock type mock-ups.

\section{High Heat Flux Test Facility and HHF tests}

Recently we have established a High Heat Flux Test Facility (HHFTF) at IPR, India, to test small scale mock-ups as well as whole divertor targets. Figure 2 shows a photograph of HHFTF established at IPR. Two types of tungsten monoblock type test mock-ups were tested using HHFTF. Both of the test mock-ups successfully sustained 316 thermal cycles with

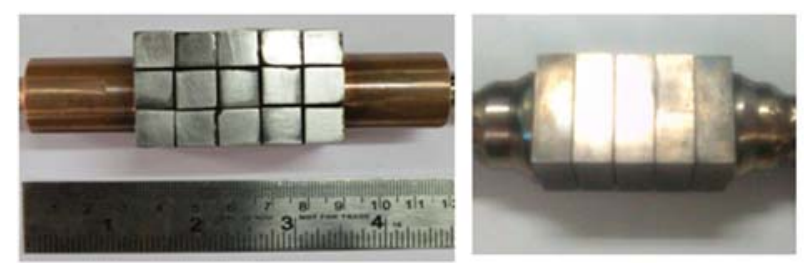

Fig. 1. Tungsten macro-brush type mock-up and tungsten monoblock type mock-up.

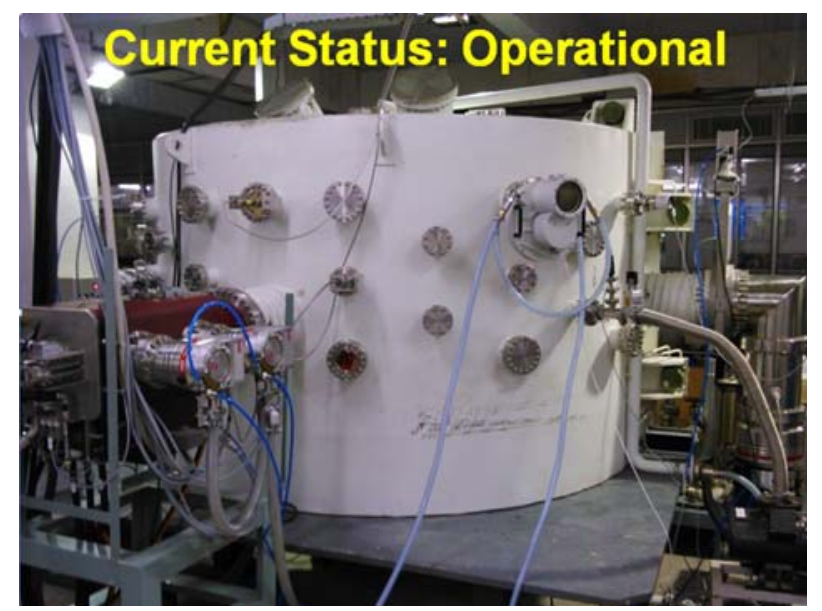

Fig. 2. High Heat Flux Test Facility (HHFTF) at IPR. 


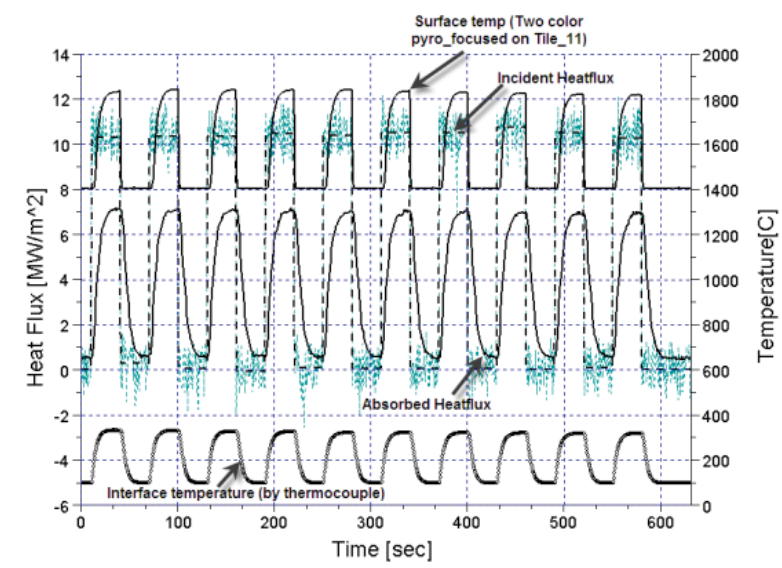

Fig. 3. Thermal cyclic performance of a graphite macro-brush type test mock-up.

absorbed heat flux of $10 \mathrm{MW} / \mathrm{m}^{2}$ during HHF tests. Previous HHF tests were performed up to incident flux 19.5 MW/ $\mathrm{m}^{2}$ on tungsten macro-brush type of test mock-ups and incident heat flux $10 \mathrm{MW} / \mathrm{m}^{2}$ for graphite macro-brush type of test mock-ups fabricated by vacuum brazing technique at Plasma Materials Test Facility of Sandia National Laboratories (Albuquerque, USA) [7, 8]. Figure 3 shows the thermal cyclic performance of graphite macro-brush type of test mock-up during HHF tests with absorbed heat flux $7.2 \mathrm{MW} / \mathrm{m}^{2}$ corresponding incident heat flux $10 \mathrm{MW} / \mathrm{m}^{2}$.

The maximum surface temperature observed on graphite tile was $1800^{\circ} \mathrm{C}$, measured by two colour pyrometers for the absorbed heat flux 7.2 MW/m² by coolant calorimetry with incident heat flux $10 \mathrm{MW} / \mathrm{m}^{2}$. Surface temperature measured by the IR camera is very well matched with two-colour pyrometer focused on the tile number 11 of the graphite macro-brush type test-mock-up. Transient infrared thermography has been performed on the test mock-ups before and after HHF tests.

\section{Transient infrared thermography}

Transient infrared thermography of macro-brush and monoblock type mock-ups has been done with the help of in-house IR thermography set-up. It consists of hot and cold water loop and FLIR IR camera SC5200M. The heat sink of the test mock-up (tungsten/graphite) was connected to a water loop system. The water loop was connected to a cold water supply (at the room temperature) and a hot water supply $\left(80^{\circ} \mathrm{C}\right)$. An IR camera is used to scan the surface temperature of the mock-up at $50 \mathrm{~Hz}$ full frame rate. A defect present at a joint and inside the mock-up will manifest itself as a fluctuation in the surface temperature of the test mock-up monitored by the IR camera. A tile with a defect shows higher surface temperature as compared to other tiles or reference tile. The surface temperature of each tile $(T(t))$ is normalized with respect to a stable cold temperature $\left(T_{c}\right)$ and stable hot temperature $\left(T_{h}\right)$ for realization of stable inspection. A normalized temperature for each tile was calculated using Eq. (1). The maximum temperature difference for other tiles with respect to reference tile is referred as DTref. DTref of each tile was calculated by considering good bonded tile as a reference tile (using Eq. (2)). Reference tile or defect free tile was identified by the tile performance during cooling and heating of the mock-up as well as finite element analysis (FEA). A tile having high heating and cooling rate as compared to other tiles is adopted as a reference tile.

This experimental procedure was carried out on both the macro-brush type mock-ups before and after high heat flux tests.

$$
T_{\text {normalized }}=\left(T_{\text {measured }}-T_{c}\right) * \frac{\left(\tilde{T}_{h}-\tilde{T}_{c}\right)}{\left(T_{h}-T_{c}\right)}+\tilde{T}_{c}
$$

where $T_{c}$ and $T_{h}$ are the cold and hot stable temperature of the tile, and $\tilde{T}_{c}$ and $\widetilde{T}_{h}$ are the averaged cold and hot stable temperatures of all tiles $[9,10]$.

$$
\text { DTref }=\mathrm{T}_{\text {ref }}-\mathrm{T}_{\text {tile }}
$$

The maximum temperature difference for other tiles with respect to the reference tile is referred to as 'DTref ${ }_{\text {max }}$ ' and used to define the acceptance limit for macro-brush type mock-ups. Graphite tiles having DTref $_{\text {max }} \sim 3^{\circ} \mathrm{C}$ before the HHF test show good performance during the HHF tests. The surface temperature observed on the graphite tiles is approximately $\sim 1400^{\circ} \mathrm{C}$ during $\mathrm{HHF}$ tests with absorbed heat flux $7.2 \mathrm{MW} / \mathrm{m}^{2}$, which is consistent with expectations based on a finite element analysis (FEA), as shown in Fig. 4. Tiles having DTref $\mathrm{Dax}_{\max }>3^{\circ} \mathrm{C}$ are rejected and the surface temperature observed during HHF tests reaches values $>1400^{\circ} \mathrm{C}$. The tile number 11 of the graphite mock-ups shows maximum DTref $_{\max }>3^{\circ} \mathrm{C}$ before $\mathrm{HHF}$ and the surface temperature $\sim 1800^{\circ} \mathrm{C}$.

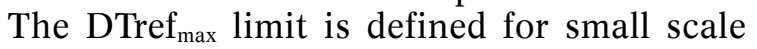
macro-brush type mock-up as shown in Fig. 5. The acceptance criteria DTref ${ }_{\max }$ limit for the graphite macro-brush mock-up is $\sim 3^{\circ} \mathrm{C}$, while for tungsten macro-brush mock-up it is $\sim 5^{\circ} \mathrm{C}$. Figure 5 shows the DTref $_{\max }$ and the surface temperature observed on graphite tiles during HHF tests correlation. Graphite

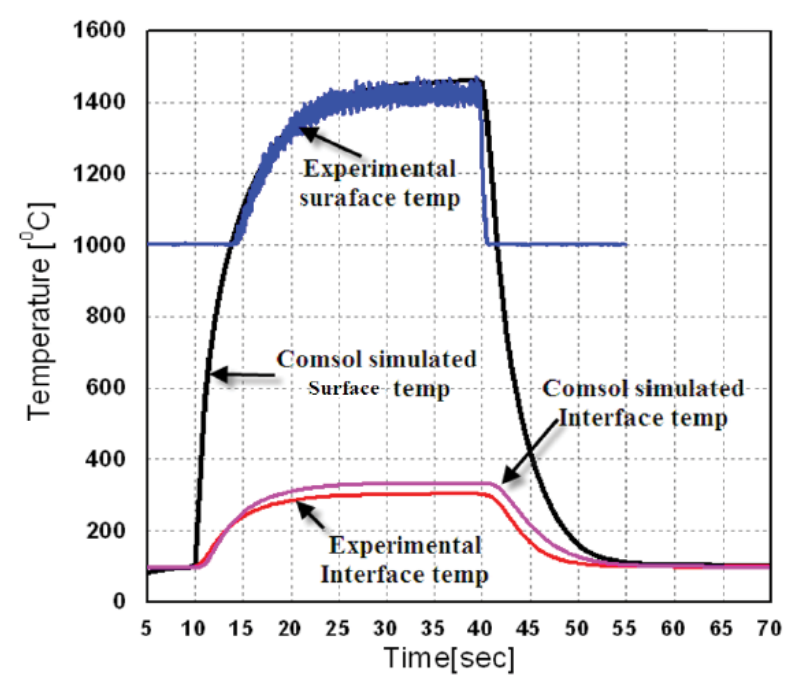

Fig. 4. Finite element analysis results for the graphite test mock-up during HHF test, carried out using COMSOL Multiphysics software for the absorbed heat flux $7.2 \mathrm{MW} / \mathrm{m}^{2}$. 


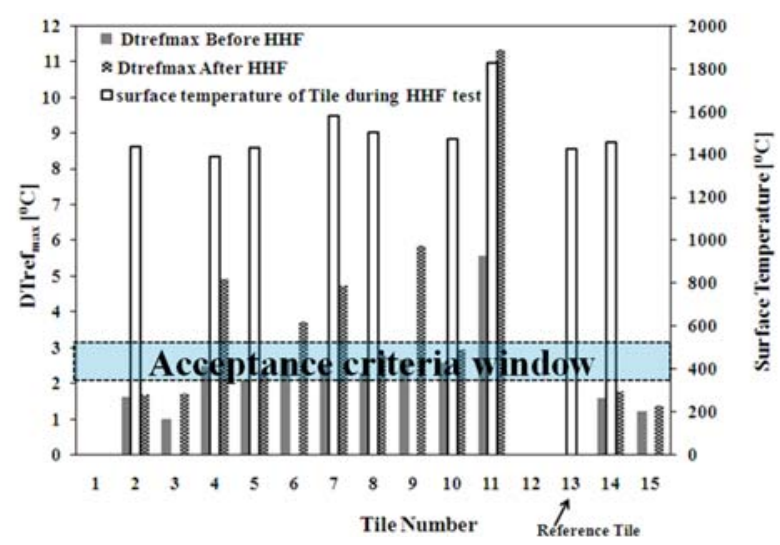

Fig. 5. DTref $f_{\max }$ and the surface temperature observed during HHF tests correlation for graphite macro-brush type mock-up.

tiles 1 and 12 were detached from the mock-up before HHF tests while surface temperature of graphite tile 3 is less than the IR camera temperature range $1000-3000^{\circ} \mathrm{C}$.

\section{Summary and conclusions}

The Divertor and First Wall Technology Development Division at the IPR has indigenously developed macro-brush type and monoblock type test mock-ups for divertor applications. Both geometries can survive an absorbed heat flux of up to $10 \mathrm{MW} / \mathrm{m}^{2}$. Transient infrared thermography set-up as well as HHFTF facility have been established at IPR to check the heat transfer behavior of divertor PFCs. Acceptance criteria have been defined for small-scale macro-brush type test mock-ups. Acceptance criteria DTref $_{\text {max }}$ limit for graphite macro-brush mock-ups is $\sim 3^{\circ} \mathrm{C}$ while for tungsten macro-brush mock-ups is $\sim 5^{\circ} \mathrm{C}$.

Acknowledgment. The authors would like to thank National Aerospace Laboratories (NAL), Bangalore, Sandia National Lab, USA, SATIR, CEA Cadarache, NFTDC, and Hyderabad, India. The authors would also like to thank all members of Divertor \& First Wall Technology Development Division and IR Thermography, Charge Exchange \& Motional Stark Effect Division of the Institute for Plasma Research for their support during various activities involved in this work.

\section{References}

1. Merola, M., Danner, W., Pick, M., \& the UE ITER Participating Team. (2005). EU R\&D on divertor components. Fusion Eng. Des., 75/79, 325-331.

2. Linke, J. (2006). Plasma facing materials and components for future fusion devices - development, characterization and performance under fusion specific loading conditions. Phys. Scripta, T123, 45-53. DOI: 10.1088/0031-8949/2006/T123/006.

3. Merola, M., Palmer, J., \& the UE ITER Participating Team. (2006). EU acitivities in preparation of the procurement of the ITER divertor. Fusion Eng. Des., 81, 105-112.

4. Durocher, A., Vignal, N., Escourbiac, F., Farjon, J. L., Schlosser, J., \& Cismondi, F. (2005). Development of an original active thermography method adapted to ITER plasma facing components control. Fusion Eng. Des., 75/79, 401-405.

5. Khirwadkar, S. S., Singh, K. P., Patil, Y., Khan, M. S., Buch, J. J., Patel, A., Tripathi, S., Jaman, P. M., Rangaraj, L., \& Divakar, C. (2011). Fabrication and characterization of tungsten and graphite based PFC for divertor target elements of ITER like tokamak application. Fusion Eng. Des., 86, 1736-1740.

6. Patil, Y., Khirwadkar, S. S., Krishnan, D., Patel, A., Tripathi, S., Singh, K. P., \& Belsare, S. M. (2013). High heat flux performance of brazed tungsten macrobrush test mock-up for divertors. J. Nucl. Mater., 437, 326-331.

7. Singh, K. P., Pandya, S. P., Khirwadkar, S. S., Patel, A., Patil, Y., Buch, J. J. U., Khan, M. S., Tripathi, S., Pandya, S., Govindrajan, J., Jaman, P. M., \& Rathore, D. (2011). Pre-qualification of brazed plasma facing components of divertor target elements for ITER like tokamak application. Fusion Eng. Des., 86, 1741-1744.

8. Patil, Y., Khirwadkar, S. S., Belsare, S. M., Rajamannar, Swamy, Khan, M. S., Tripathi, S., Bhope, K., Krishnan, D., Mokaria, P., Patel, N., Antwala, I., Galodiya, K., Mehta, M., \& Patel, T. (2015). Performance of straight tungsten mono-block test mock-ups using new high heat flux test facility at IPR. Fusion Eng. Des., 95, 84-90.

9. Mitteau, R., \& et al. (1996). Non destructive testing of actively cooled plasma facing components by means of thermal transient exciation and infrared imaging. In Proceedings of 19th Symposium on Fusion Technology (SOFT), September 16-20, 1996 (pp. 443-446). Lisbonne.

10. Durocher, A., Escourbiac, F., Richou, M., Vignal, N., Merola, M., Riccardi, B., Cantone, V., \& Constans, S. (2009). Infrared thermography inspection of the ITER vertical target qualification prototypes manufactured by European industry using SATIR. Fusion Eng. Des., 84, 314-318. 